\title{
Communal nesting is unrelated to burrow availability in the common warthog
}

\author{
Angela M. White ${ }^{\mathrm{a}, *}$, Elissa Z. Cameron ${ }^{\mathrm{b}, 1}$ \\ a Program in Ecology, Evolution and Conservation Biology, University of Nevada-Reno \\ ${ }^{\mathrm{b}}$ Mammal Research Institute, University of Pretoria, South Africa
}

\section{A R T I C L E I N F O}

\section{Article history:}

Received 11 June 2008

Initial acceptance 30 June 2008

Final acceptance 11 August 2008

Available online $\mathrm{xxx}$

MS. number: A08-00392R

\section{Keywords:}

common warthog

communal nesting

cooperative breeding

ecological constraints

habitat choice

Phacochoerus africanus

reproductive strategies

site selection

sociality

\begin{abstract}
Warthogs, Phacochoerus africanus, are an unusual ungulate. They are facultative cooperative breeders where females within the same population display both solitary and cooperative reproductive strategies. Warthogs require burrows for sleeping and rearing their young, yet they are unable to dig their own burrows and rely on aardvark excavations. Studies of warthogs have failed to show any reproductive benefits to females participating in communal care and suggest a reproductive cost to cooperation. The ecological constraints hypothesis proposes that environmental factors limit an individual's ability to successfully disperse and reproduce. In this study we investigated whether limitations in burrow sites can explain cooperative breeding in this species. We checked over 500 burrows for signs of use systematically for 1 year to determine whether burrows were a limiting resource and to investigate burrow use preferences. Our methodology allowed us to determine whether burrows were used by adults with young or by adults without young. We found that burrow availability did not appear to pose an ecological constraint on independent living, as the percentage of burrows used remained relatively low throughout the year. Additionally, the number of burrows in a warthog clan area did not influence the percentage of females breeding cooperatively. Predator avoidance appeared to be the main factor influencing individual burrow selection by warthogs and communal nesting may best be explained as a form of antipredator behaviour.

(C) 2008 The Association for the Study of Animal Behaviour. Published by Elsevier Ltd. All rights reserved.
\end{abstract}

Cooperative breeding occurs when members of a social group assist with the rearing of offspring that are not genetically their own (Emlen 1991). Such assistance includes systems in which nonreproductive individuals assist in the rearing of others' young, or when reproductive individuals share in offspring care with other reproductive members of their social group (Solomon \& French 1997). Studies on cooperative breeding have highlighted some of the selective pressures leading individuals to delay dispersal from their natal range and assist in the rearing of others' offspring, while often delaying their own reproduction (reviewed by Cockburn 1998). For example, cooperative breeding is often seen when dispersal opportunities are ecologically constrained, such as when habitat is saturated, when there are few mating opportunities, or when there is a low probability of successful dispersal (Emlen 1994, 1982).

While ecological constraints has been a useful framework for understanding delayed dispersal in birds, its applicability to mammals has been questioned (Russell 2004). However, many cooperatively breeding mammals use specialized burrows for living

\footnotetext{
* Correspondence: A.M. White, Program in Ecology, Evolution and Conservation Biology, University of Nevada-Reno, 1000 Valley Road, Reno, NV 89512, U.S.A.

E-mail address: amwhite@unr.edu (A.M. White).

1 E.Z. Cameron is at the Mammal Research Institute, Department of Zoology and Entomology, University of Pretoria, Pretoria 0002, South Africa.
}

or rearing their young (e.g. rodents: Hayes 2000; mongooses: Rood 1986; canids: Moehlman \& Hofer 1997). In these species, dispersal may be constrained by the energetic costs of excavating or maintaining burrows (Lovegrove 1989; Jarvis et al. 1994) or by the predation risks associated with attempting to locate, construct or modify burrows (Ebensperger \& Bozinovic 2000). Thus, individuals may share burrow or denning sites because a species' reliance on these structures makes dispersal costs prohibitive. Alternatively, individuals may share burrow sites because they gain direct or indirect benefits by forming groups with conspecifics. These benefits can include decreased thermoregulatory costs, acquisition of resources and skills and group predator defence (reviewed in Hayes 2000).

Although group living is common in many ungulate species, cooperative offspring care is rare (Russell 2004). Warthogs are unique among the ungulates. They are facultative cooperative breeders, displaying both solitary and cooperative-breeding strategies within a population in roughly equal proportions (Cumming 1975; Somers et al. 1995). They are also unusual for an ungulate in that they sleep in burrows each night, and use burrows for protection against predators, for thermoregulation and for giving birth (Estes 1991). Additionally, whereas in most species one sex will disperse, philopatry is common in male and female warthogs, although females are predominately the helping sex (Cumming 1975; Somers et al. 1994; Muwanika et al. 2006). Cooperative breeding in this species includes single breeding females with 
nonreproductively aged helper(s) and two or more females rearing their young communally (Cumming 1975; Somers 1992). These cooperative associations can occur over successive years and include the sharing of burrow sites to rear their young (Cumming 1975; Mason 1982). Finally, compared to most ungulates, warthogs are fecund, with up to eight piglets produced per litter (Estes 1991). Previous work on cooperative breeding in warthogs suggests that neither group size nor the number of females rearing offspring communally affects juvenile survival (Plesner Jensen et al. 1999), and therefore, the warthog's unique life history characteristics may account for their propensity to breed cooperatively because of dispersal constraints.

Use of burrows is common for diurnal species that experience high predation pressure, and the unusual use of burrows by warthogs may be best explained by their susceptibility to predation (Spinage 1972). As all available burrows may not satisfactorily meet the needs of a warthog, burrow type and distribution may be more important than actual numbers. For example, the habitat in which a burrow is located can influence its use by providing cover from predators and proximity to feeding areas (Schradin \& Pillay 2006; Hayes et al. 2007). Similarly, soil can influence vegetation type, affect the ability of fossorial species and predators to excavate and modify burrows, and can influence burrow humidity (Kinlaw 1999). Predator defence and evasion are likely to influence choice of burrows by warthogs since, compared to other savannah ungulates, warthogs lack speed and endurance and retreat to the confines of a burrow when pursued (Estes 1991). Warthogs, therefore, may preferentially use burrows with shorter entrances that inhibit predators from entering or that provide refuge close to favoured feeding areas. Reproductive females may also require specific types of burrows for giving birth and rearing their young, including characteristics that decrease infanticide by larger males (Somers et al. 1995), such as burrows with smaller entrances or in more isolated areas, burrows closer to water to meet the demands of lactation, or burrows located in harder soils that limit a predator's ability to dig them out. If burrows with preferred characteristics are a limiting resource, then the costs of sharing a desirable burrow may be less than the costs associated with independent use of less suitable burrows.

In this study we investigated whether limitations in burrows may influence the incidence of cooperative breeding in warthogs through ecological constraint. Warthogs use several burrows, which are shared simultaneously with other members of their social group and sequentially with other groups with overlapping home ranges (Cumming 1975; Somers 1992). Consequently, burrows could be a limiting resource for warthogs, since (1) warthogs do not dig their own burrows, relying instead mostly on aardvark excavations (Cumming 1975), (2) warthogs not only compete intraspecifically for access to these burrows, but also with several other species including hyaenas, wild dogs and porcupine (Somers 1992) and (3) predators may destroy burrows as they attempt to dig out their prey (Cumming 1975; Funston et al. 2001). The time of year may also influence burrow availability. For example, most interspecific competition over burrows is temporally segregated because of the diurnal nature of warthogs and the nocturnal nature of their competitors. However, during the farrowing (i.e. birthing) season, adults leave their offspring in a burrow during the day and therefore compete directly with other species for burrow access during this time.

\section{METHODS}

\section{Study Area}

We conducted this study between August 2004 and November 2005 in the iMfolozi Section of Hluhluwe-iMfolozi Park (HiP), in the
KwaZulu-Natal province of South Africa $\left(28^{\circ} \mathrm{S}, 31^{\circ} \mathrm{E}\right)$. HiP is a $965 \mathrm{~km}^{2}$ fenced game reserve, with the iMfolozi section being composed predominately of savannah/bushveld habitat. Average annual rainfall in iMfolozi is $650 \mathrm{~mm}$, with most rain occurring in the summer months between October and March. With the exception of a few springs, the Black and the White iMfolozi Rivers are the only permanent water sources in this area. In addition to warthogs, iMfolozi is home to a full guild of herbivores and contains several warthog predators (Cumming 1975) including African lion, Panthera leo, spotted hyaena, Crocuta crocuta, leopard, Panthera pardus, cheetah, Acinonyx jubatus, and African wild dog, Lycaon pictus. In 2004, warthog densities in iMfolozi were estimated at 3.89 warthogs per $\mathrm{km}^{2}$. In southern Africa, warthogs give birth once a year in late-October/early November (Skinner \& Chimimba 2005).

\section{Burrow Classification}

We identified 510 burrows used by warthogs within a $30 \mathrm{~km}^{2}$ study area in the southern section of iMfolozi Game Reserve. Some characteristics of burrows can be measured externally, while other measurements require internal exploration. We investigated only a small subset (10\%) internally, by crawling through the burrow entrance, because of the risks associated with the accidental encounter of an animal inside the burrow. Our exploration of these burrows did, however, reveal that burrows varied greatly in their shape and complexity. We found that the most common burrow type included an entrance tunnel terminating in a circular chamber. Burrows differed in the circumference, length and curvature of their entrance tunnel, as well as the size, shape and number of chambers, the slope and slope complexity of the burrow and the number of entrances. Our observations are consistent with previous descriptions of burrows (Cumming 1975; Mason 1982). Additionally, we found that the dimensions of a burrow can change rapidly because of erosion and periodic excavation. For these reasons, characteristics included in this study were limited to features that could be measured externally and reliably. Obvious burrow changes were noted during biweekly sampling.

For each burrow we recorded its GPS location and measured the entrance height and entrance width. Based on the location, we identified the soil type and surrounding habitat type using preexisting GPS maps. Habitat was classified into six structural vegetation types based on the canopy cover (Grassland, Open woodland, Medium woodland) and understory thickness (Open thicket, Medium thicket, Dense thicket) using a vegetation map generated from Landsat ETM bands (Dora 2004). We found burrows in all available habitat types. Burrows were found primarily in five soil types (Table 1). Burrows found in other types of soil were rare and classified as 'Other' for analysis. Distance to a permanent water source and burrow densities were calculated using ArcMap (ESRI, Redlands, CA, U.S.A.).

\section{Burrow Use}

We systematically checked burrows on sampling days by walking one of six established routes such that individual burrows were checked every 14 days (range 7-21 days) for evidence of use by warthogs and other semifossorial species. We recorded whether a burrow had been used, and by what species, based on footprints leading into the burrow. For burrows used by warthogs, we determined whether the burrows had been used by a mother with young, based on the presence of two distinct footprint sizes, but no other social class could be reliably distinguished. After establishing whether a burrow had been used, we swept the entrance smooth. Unused burrows were also swept to standardize any disturbance from our methodology. Consequently, when we next visited the burrow we could determine whether the burrow had been used in 
Table 1

Mean \pm SE percentage of burrows used by warthogs, by habitat and soil types across seasons

\begin{tabular}{|c|c|c|c|c|c|c|c|c|c|c|c|c|}
\hline & \multicolumn{6}{|c|}{ Habitat type } & \multicolumn{6}{|l|}{ Soil type } \\
\hline & $\begin{array}{l}\text { Grassland } \\
(N=39)\end{array}$ & $\begin{array}{l}\text { Open } \\
\text { woodland } \\
(N=156)\end{array}$ & $\begin{array}{l}\text { Medium } \\
\text { woodland } \\
(N=22)\end{array}$ & $\begin{array}{l}\text { Open } \\
\text { thicket } \\
(N=69)\end{array}$ & $\begin{array}{l}\text { Medium } \\
\text { thicket } \\
(N=77)\end{array}$ & $\begin{array}{l}\text { Dense } \\
\text { thicket } \\
(N=49)\end{array}$ & $\begin{array}{l}\text { Alluvia } \\
(N=172)\end{array}$ & $\begin{array}{l}\text { Shortland } \\
(N=23)\end{array}$ & $\begin{array}{l}\text { Swartland } \\
\text { (sand) } \\
(N=51)\end{array}$ & $\begin{array}{l}\text { Swartland } \\
\text { (no sand) } \\
(N=104)\end{array}$ & $\begin{array}{l}\text { Valsrivier } \\
(N=35)\end{array}$ & $\begin{array}{l}\text { Other } \\
(N=27)\end{array}$ \\
\hline Warthogs & $44.3 \pm 3.0$ & $37.9 \pm 1.0$ & $37.9 \pm 2.7$ & $33.9 \pm 1.5$ & $42.3 \pm 1.6$ & $36.2 \pm 2.3$ & $40.4 \pm 1.2$ & $40.5 \pm 3.1$ & $36.4 \pm 2.0$ & $37.9 \pm 1.5$ & $32.6 \pm 2.3$ & $43.4 \pm 3.0$ \\
\hline Summer/Farrow & $47.2 \pm 4.5$ & $39.9 \pm 2.1$ & $34.0 \pm 5.0$ & $38.6 \pm 2.4$ & $36.0 \pm 2.8$ & $30.4 \pm 3.5$ & $38.6 \pm 2.0$ & $43.7 \pm 5.1$ & $38.5 \pm 3.3$ & $33.9 \pm 2.3$ & $31.5 \pm 4.3$ & $49.8 \pm 6.2$ \\
\hline Winter & $43.6 \pm 3.1$ & $37.5 \pm 1.1$ & $39.5 \pm 3.1$ & $32.2 \pm 1.7$ & $43.6 \pm 1.6$ & $37.7 \pm 2.5$ & $40.7 \pm 1.2$ & $40.0 \pm 3.4$ & $35.7 \pm 2.1$ & $38.3 \pm 1.6$ & $32.7 \pm 2.4$ & $43.0 \pm 3.2$ \\
\hline $\begin{array}{l}\text { Reproductive } \\
\text { females }\end{array}$ & $7.1 \pm 1.8$ & $3.2 \pm 0.4$ & $1.5 \pm 0.6$ & $2.2 \pm 0.3$ & $3.0 \pm 0.4$ & $3.3 \pm 0.8$ & $3.3 \pm 0.4$ & $4.9 \pm 1.8$ & $2.6 \pm 0.6$ & $3.9 \pm 0.6$ & $2.5 \pm 0.8$ & $3.0 \pm 1.0$ \\
\hline Summer/Farrow & $5.8 \pm 2.3$ & $5.5 \pm 1.0$ & $0.8 \pm 0.8$ & $2.9 \pm 0.9$ & $3.2 \pm 0.8$ & $2.6 \pm 1.0$ & $4.1 \pm 0.8$ & $6.3 \pm 2.4$ & $3.8 \pm 1.5$ & $3.8 \pm 1.0$ & $2.8 \pm 1.4$ & $5.0 \pm 2.1$ \\
\hline Winter & $7.1 \pm 2.1$ & $2.8 \pm 0.4$ & $1.8 \pm 0.8$ & $2.0 \pm 0.4$ & $3.1 \pm 0.5$ & $3.5 \pm 0.9$ & $3.2 \pm 0.9$ & $4.9 \pm 2.3$ & $2.3 \pm 0.7$ & $3.8 \pm 0.7$ & $2.4 \pm 0.8$ & $3.0 \pm 1.1$ \\
\hline
\end{tabular}

the specific 2-week period. Burrows were used repeatedly throughout the study, indicating that our methodology did not discourage use of burrows by warthogs.

All burrows included in the analyses were used by warthogs at least once during the course of the study. To ensure that we included only suitable warthog burrows in the analyses, we required a burrow to be used by warthogs for greater than $15 \%$ of the sampling checks. This methodology allowed us to address whether warthogs expressed a preference for certain aspects of burrows based on frequency of burrow use and was not designed to test whether certain burrow characteristics precluded use by warthogs. The number of burrows sampled biweekly increased over the course of the study as additional burrows were found and also varied depending on the formation and destruction of individual burrows (mean number of burrows checked $\pm \mathrm{SE}$ : $334.2 \pm 20.8)$. Each individual burrow was sampled 4-33 times over the course of the study $(22.3 \pm 0.3)$.

\section{Effect of Local Density on Communal Use of Burrows}

When checking burrows for use we could not distinguish between burrows that had been used repeatedly by a single warthog and burrows that had been used by a group of warthogs. To help distinguish between sequential and simultaneous use of burrows we recorded all sightings of warthogs above ground while checking burrows. Data collected on radiocollared females confirmed that above-ground grouping behaviour was a reliable surrogate for grouping behaviour below ground, as females found in association with other individuals during the day sleep in the same burrow at night (Somers 1992; A. M. White, unpublished data).

Warthogs live in clans that contain several individuals whose home ranges overlap considerably with other clan members, but are distinct from the home ranges of warthogs belonging to other clans (Cumming 1975). Because of their spatial organization, we were able to use sightings of individually recognizable warthogs to construct clan areas for analyses. Using a $K$-cluster analysis (SPSS, version 14.0, Chicago, IL, U.S.A.), we categorized sightings of warthogs into clans based on their location. Cluster number $(N=7)$ was determined subjectively by maximizing the percentage of sightings of a known individual into a single cluster while minimizing clustering of identifiable warthogs that were never seen in spatial proximity to each other. Based on the cluster assignments of our sightings data, we calculated clan areas using a minimum convex polygon (MCP) approach (Mohr 1947). We then generated a density index by summarizing the total number of dependently aged warthogs sighted within each clan area over 1-year period by the size of the clan area. We similarly assigned burrows to particular clan areas, but considered burrows as accessible to a clan if they were within $100 \mathrm{~m}$ of a clan's MCP.
The capture and marking of individuals for later identification was undertaken by experienced reserve staff trained specifically in the capture of ungulate species (Ezemvelo KwaZulu Natal Wildlife's Game Capture Unit). Most warthogs were captured by net without chemical immobilization. Once caught, animals were quickly removed from the net and manually restrained long enough to attach a collar or notch the ears ( $5 \mathrm{~min}$ ) before being released. In some cases the use of nets was not feasible and some individuals were immobilized using Zoletil $^{\circledR}$ or etorphine hydrochloride following the guidelines of Burroughs (1993) on the chemical capture of warthog. To minimize heat stress, all trapping of warthogs were conducted during early morning and late afternoon hours. Warthogs were permanently marked by clipping a small notch $(1 \mathrm{~cm})$ out of the ear(s). Ear notching is the most effective method for later identification of warthogs as eartags readily fall or are ripped out of the ear (Cumming 1975; Somers 1992). To locate specific individuals regularly, we collared several fully grown female warthogs using VHF collars weighing $0.6 \mathrm{~kg}$, which is less than $0.02 \%$ of the animals' body weight. Permission to conduct this research was given by Ezemvelo KwaZulu-Natal Wildlife, and the capture procedures and methods were approved by the University of Nevada, Reno's Animal Care and Use Committee.

\section{Statistical Analysis}

Parametric analyses were performed using general linear modelling in SPSS. Univariate analysis was used to determine whether burrow characteristics influenced the frequency with which burrows were used by warthogs, with habitat type and soil type treated as categorical fixed effects. Entrance height, entrance width, distance to permanent water and burrow density were treated as covariates in the model. We additionally used a repeated measures approach to investigate whether season affected use of individual burrows. Frequency of burrow use was calculated separately for the period of October to March corresponding to the wet, summer months when parturition and early offspring dependence occur and for the period of April to September during the dry, winter months outside of the birthing season. We performed this analysis in addition to the previous analysis described because our sample size was reduced substantially using a repeated measures approach as a result of missing data in one of the two seasons. We present partial eta-squared values as a measure of effect size (Cohen 1988) for all general linear models.

We performed additional analyses considering only those burrows that had been used by reproductive females. Variables pertaining to the use of burrows by reproductive females did not meet the assumptions of parametric analyses, so we analysed categorical independent variables using a Kruskal-Wallis test and we analysed the relationship between burrow use and continuous independent variables using Spearman rank correlations. We conducted analyses for overall use during the summer months 
(birthing season) and during the winter months separately. These analyses were conducted to determine whether burrow preferences were affected by different variables for this social group and to help elucidate whether any seasonal differences in burrow use between the two time periods could be attributed to seasonal effects or birthing requirements.

We investigated the relationship between clan densities and the percentage of cooperative groups using Spearman rank correlations. Specifically, we tested whether the number of available burrows per individual influenced group sizes or the percentage of reproductive females found in cooperative groups. Adult males were excluded from our estimates of group size because outside of the mating season they were rarely found in groups and, therefore, sociality appears to be constrained for adult males (Cumming 1975; A. M. White, unpublished data). All tests were two tailed and significance was set at $P<0.05$. Means are presented with standard errors throughout.

\section{RESULTS}

\section{Burrow Limitations}

The percentage of burrows used on a biweekly basis ranged from 25.1 to $59.6 \%(38.8 \pm 1.6)$. Since the number of burrows inspected during each sampling period varied, we tested whether this variability influenced the percentage of burrows used. The number of burrows inspected during a sampling period did not influence the percentage of burrows recorded as used $\left(F_{1,32}=1.37\right.$, $P=0.25)$. Burrow usage peaked in January and then decreased significantly over time $\left(F_{1,10}=9.24, R^{2}=0.43, P=0.01\right.$; Fig. 1$)$. During the study, we identified several species using the burrows based on their footprints, including warthog, aardvark, Orycteropus afer, porcupine, Hystrix africaeaustralis, spotted hyaena, African wild dog, genets (Genetta sp.), greater cane rats, Thryonomys swinderianus, horseshoe bats (Rhinolophus sp.) and snakes. Burrow usage by these species was low, ranging from 0 to $10.7 \%(3.35 \pm 0.4$; Fig. 1). Since burrow use was highest in January, any burrow constraints would be more likely during this time of year. The percentage of cooperatively breeding females sighted each month above ground was unrelated to the percentage of burrows used (Spearman rank correlation: $r_{\mathrm{S}}=0.355, N=12, P=0.26$; Fig. 1 ).

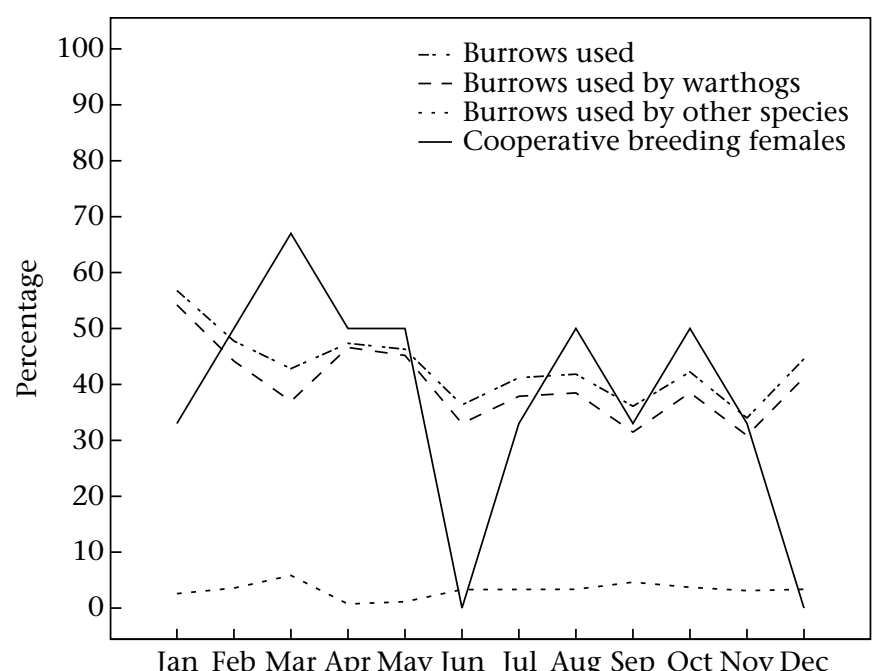

Figure 1. Average monthly use of available burrows by warthogs, by other species and by all species combined, and the percentage of female warthogs found breeding in cooperation.

\section{Burrow Preferences}

Use of individual burrows ranged from 15 to $100 \%(38.1 \pm 15.3)$, and the variability was not affected by the number of times that an individual burrow had been sampled $\left(F_{1,508}=0.003, P=0.96\right)$. We found no evidence that the main effects of habitat type $\left(F_{5,379}=1.48, \quad P=0.20, \eta_{p}^{2}=0.02\right.$, $)$ or soil type $\left(F_{5,379}=0.39\right.$, $\left.P=0.85, \eta_{p}^{2}=0.01\right)$ influenced choice of burrows by warthogs (Table 1). Additionally, we found that burrow use did not significantly vary with either the entrance height $\left(F_{1,379}=0.27, P=0.61\right.$, $\eta_{p}^{2}=0.00$; Fig. 2a) or distance to water $\left(F_{1,379}=0.03, P=0.87\right.$, $\eta_{p}^{2}=0.00$; Fig. 2d). Burrow use was however, negatively associated with burrow density $\left(F_{1,379}=9.24, P=0.003, \eta_{p}^{2}=0.02\right.$; Fig. $\left.2 c\right)$ and positively related to entrance width $\left(F_{1,379}=5.31, P=0.02\right.$, $\eta_{p}^{2}=0.01$; Fig. $\left.2 \mathrm{~b}\right)$, although these factors explained little variation in burrow use. Choice of burrows used by warthogs was largely unaffected by season; however, use of burrows based on burrow density changed as a function of season. Warthogs were less likely to use burrows in areas with higher densities of burrows during the winter months than during the summer months (Table 2). Burrows for which we had data across seasons tended to be used more during the winter months $(39.4 \pm 0.1)$ than during the summer months $(37.9 \pm 1.3)$.

\section{Burrow Use by Reproductive Females}

Although differences in statistical tests make direct comparisons difficult, reproductive females appeared to be more selective in their choice of burrows than all warthogs combined (Table 3). Similar to burrows used by all warthogs, a reproductive female's choice of burrow appeared unaffected by habitat or soil type (Table 1 ), but adult female burrow selection was negatively influenced by burrow height (Fig. 2a) and density (Fig. 2c) and tended to be positively influenced by the width of the burrow entrance (Fig. 2b) and distance to a permanent water source (Fig. 2d, Table 3). Choice of burrows by reproductive females during the winter months reflected overall preferences, with the correlation between the percentage of time that individual burrows were used and the distance to water becoming significant. Therefore, reproductive females preferentially used burrows that were shorter in height and in areas of lower burrow density and tended to prefer wider burrow entrances and burrows closer to water. However, during the summer months, when parturition occurs, choice of burrows by reproductive females was not influenced by any of the independent variables tested.

\section{Effect of Clan Density on Cooperation}

The average number of warthogs sighted in each clan area $(N=7)$ during the year was $18.4 \pm 3.6$ (range 8-36). Clan density indexes ranged from 14.0 to 145.5 warthogs sighted per year per $\mathrm{km}^{2}$ (mean \pm SE: $56.5 \pm 17.9$ ). Average group size, excluding the effect of solitary males, was $1.96 \pm 0.13$ (range 1.33-2.40). Clan density indexes were unrelated to average group sizes (Spearman rank correlation: $r_{\mathrm{S}}=0.57, N=7, P=0.18$ ) and the percentage of cooperative reproductive females $\left(0.76 \pm 0.08 ; r_{\mathrm{S}}=-0.34, N=7\right.$, $P=0.45)$. The average number of burrows available per the annual number of warthogs sighted per clan $(1.93 \pm 0.65$; range $0.27-4.25)$ did not influence the percentage of reproductive females breeding cooperatively $\left(r_{\mathrm{S}}=0.00, N=7, P=1.00\right)$, but tended to influence the average group size $\left(r_{\mathrm{S}}=-7.03, N=7, P=0.08\right)$.

\section{DISCUSSION}

Our results agree with previous studies suggesting that the number of available warthog burrows are ample for the population 

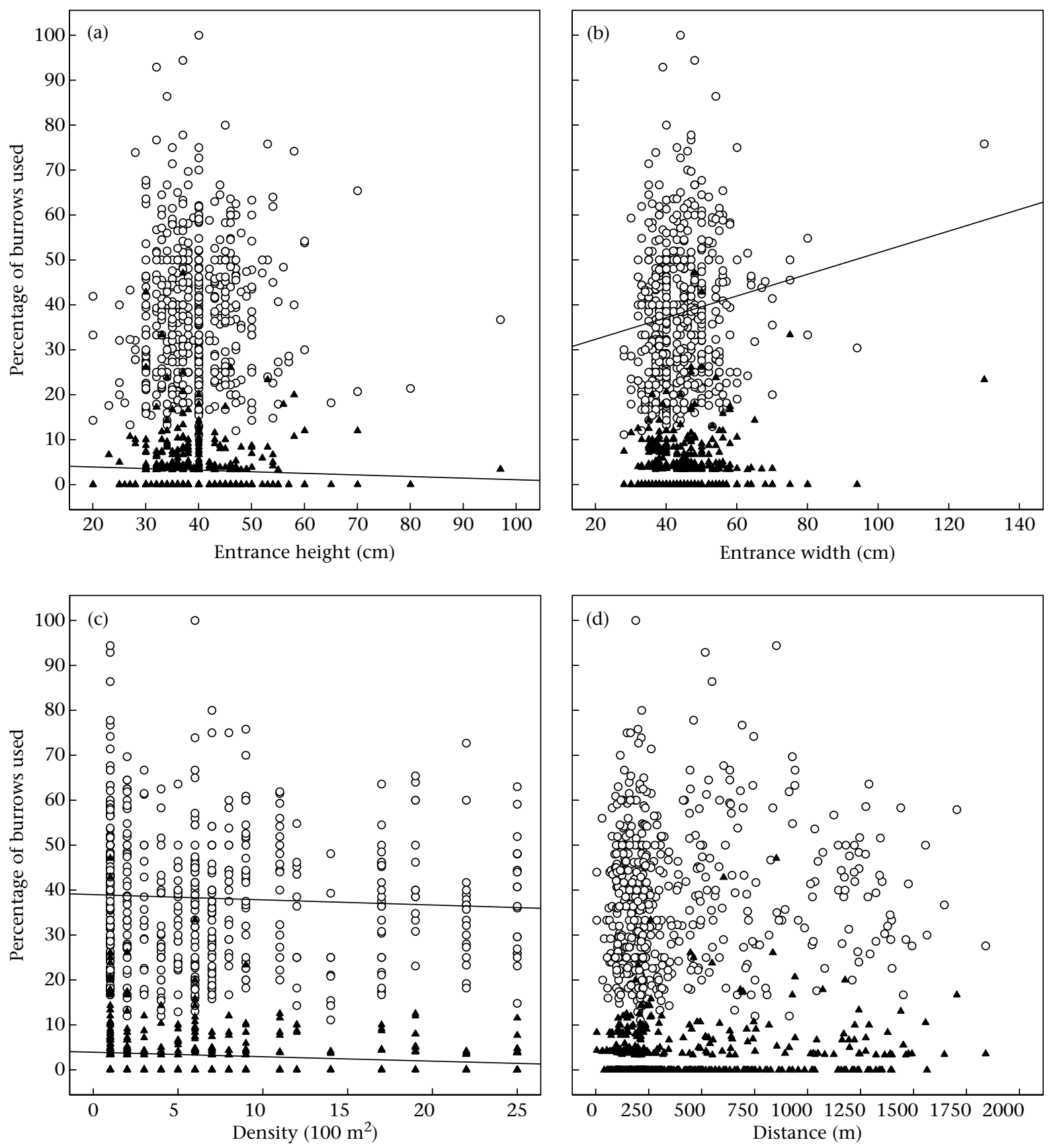

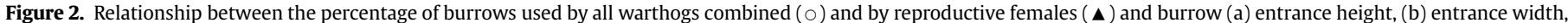
(c) density and (d) distance to water. Linear regression lines are shown.

(Cumming 1975; Mason 1982). We found that the number of available burrows did not appear to restrict independent breeding because the percentage of burrows used by warthogs on a biweekly basis remained relatively low throughout the year. Additionally, use of burrows by other species was low and did not necessarily preclude use by warthogs during the same period. The use of multiple burrows, however, suggests that several burrows may be required to meet a warthog's needs (Cumming 1975). Multiple burrows may be necessary to decrease predation, facilitate safe access to resources or to escape high parasitic burdens caused by repeated use of individual burrows. In this study, biweekly use of individual burrows suggests that burrows can be used over extended periods without apparent consequence or deterrence (see also Cumming 1975). Additionally, although certain burrow characteristics influenced the frequency with which they were used, these characteristics explained very little variability in their use, suggesting that all available burrows investigated in this study were similarly adequate. Therefore, on the basis of our data, it appears that burrow numbers are adequate for independent breeding, but any restrictions in the availability of burrows are more likely to occur in the summer months during the birthing season when a higher percentage of burrows are being used. Our findings that the number of burrows used each month and the number of burrows within a clan area were unrelated to the percentage of females breeding cooperatively supports our interpretation that limitations in burrows do not explain cooperativebreeding behaviour in warthogs.

Despite substantial variability in use of individual burrows, we found surprisingly little evidence that warthogs were selecting burrows based on the characteristics measured in this study. In 
Table 2

Factors explaining variation in use of burrows by warthogs during the summer and winter seasons

\begin{tabular}{lrlll}
\hline Factor & $d f$ & $F$ & $P$ & $\eta_{p}^{2}$ \\
\hline Season & 1 & 3.59 & 0.06 & 0.01 \\
Season*habitat & 5 & 1.70 & 0.14 & 0.03 \\
Season*soil & 5 & 0.73 & 0.60 & 0.01 \\
Season*entrance height & 1 & 1.04 & 0.31 & 0.00 \\
Season*entrance width & 1 & 1.30 & 0.26 & 0.00 \\
Season*burrow density & 1 & 4.13 & 0.04 & 0.02 \\
Season*burrow distance & 1 & 1.33 & 0.25 & 0.01 \\
Season*habitat*soil & 17 & 1.34 & 0.17 & 0.08 \\
Error (Season) & 264 & & & \\
\hline
\end{tabular}

other species, habitat is an important variable in site selection, and sites located in favoured feeding areas optimize energy expenditure and minimize exposure to predators (e.g. Sachot et al. 2003; Seryodkin et al. 2003; Zabala et al. 2003; Hayes et al. 2007). Although we found no effect of habitat structure or soil type on burrow choice, warthogs may select burrows based on differences in microhabitat (Garshelis 2000) rather than on structural differences in the landscape (this study). Warthogs do not dig their own burrows, so soil type may be less important to warthogs than it is to other species that actively build and maintain their burrows (Solomon \& Getz 1997; but see Ebensperger \& Bozinovic 2000).

Protection from predators is undoubtedly one of the main factors driving the peculiar use of burrows by warthogs. The lack of any strong preferences displayed for particular burrows may suggest that, once inside a burrow, a warthog can successfully fend off most predators. Adult warthogs often back into burrows, which positions their formidable tusks at the entrance (Estes 1991). Warthogs defend themselves by swiping their tusks laterally, so wider burrow entrances may be preferred because they enable warthogs to defend themselves, and their offspring, more effectively from inside the entrance. In contrast, shorter entrances may prevent access by predators, which are generally taller than warthogs. Predators may also influence warthog preferences for burrows in areas with lower densities of burrows. Areas with high densities of burrows may encourage higher rates of predation by increasing a predator's chances that a burrow will be occupied. Infanticide may also contribute to avoidance of higher-density areas (Ovsyanikov 1998). Although no incidences of infanticide were documented during the course of this study, it has been reported by others (Somers et al. 1995) and may influence burrow choice.

Females with young were more selective in their choice of burrows than were other warthogs. Reproductive females may have specific burrow requirements because offspring remain within the burrow for 2-6 weeks postpartum (Cumming 1975; Somers 1992). Additional requirements may include burrows that are closer to food and water resources or in habitats that minimize visibility to predators, or that are better at regulating temperature as offspring are particularly prone to the cold (Sowls \& Phelps 1966). Females with offspring selected burrows that had shorter and wider entrances, were nearer to water and in areas of lower burrow density. However, these preferences were found only during the winter months and not during the birthing season when offspring are most vulnerable to predation and infanticide, because they are frequently left unaccompanied in the burrow (Cumming 1975). As females are predicted to be more selective when their young are most vulnerable, mothers may rely on other forms of antipredator defence during this time. For example, by sharing burrows, females may reduce individual costs of predation by group defence of offspring (Hayes 2000) or through dilution effects (Hoogland 1985). Indeed, females were most selective during the winter months when the occurrence of cooperative-breeding females was lowest. Therefore, females may rely more heavily on characteristics of burrows for protection during these months.

Previous work on warthogs suggests that communal rearing of offspring is not reproductively advantageous in terms of juvenile survival (Plesner Jensen et al. 1999). Our results also suggest that communal nesting cannot be explained by constraints in the availability of burrows. Therefore, sharing of burrows with conspecifics may be beneficial because it reduces thermoregulatory costs (Jacquot \& Vessey 1994), aids in defence against predation and infanticide (Getz et al. 1992a; Ebensperger 1998) and/or facilitates exchange of information regarding critical resources or skills (Stacey \& Lignon 1987; Getz et al. 1992b; Hayes 2000) (Table 4). Indeed, burrow sharing in warthogs is not limited to reproducing females (Cumming 1975; Mason 1982; Somers 1992). Warthogs are grazing herbivores, so communal nesting in warthogs is unlikely to be explained by resource or skill acquisition (see Russell 2004). In addition, because experienced mothers will share nests, the transfer of parenting skills is less important in warthogs than it is in species with exclusively nonreproductive helpers. Therefore, the benefits of burrow sharing to nonreproductive individuals (thermoregulation and defence against predation and infanticide) and to communally nesting individuals are the same. Consequently, communal nesting and even cooperative offspring care may arise out of advantages to burrow sharing other than those of communal care of young. Alternatively, sharing of burrows may not be advantageous, but serve to maintain group cohesion above ground, where the benefits of sociality drive group formation.

The reproductive consequences of communal nesting can differ from those of cooperative breeding because not all communally nesting species are cooperative breeders (e.g. Silk 2007). Whereas the availability of burrows did not influence cooperation between reproductive females, limitations in the relative number of burrows within a clan area had a tendency to influence warthog group sizes. Although not significant, this relationship suggests that reproductive females may have priority access to burrows and that dispersal costs are higher than the costs of forming larger-than-average groups. A clan's density index was unrelated to group size, so the role of limitations in burrows in increasing the degree of sociality is supported. A warthog's reliance on burrows may increase dispersal costs relative to other species and account for this species' unusual philopatric nature. The knowledge of the location and suitability of burrows within a natal home range may increase the benefits of philopatry for both sexes.

Table 3

Factors explaining variation in burrow use by reproductive females throughout the year

\begin{tabular}{|c|c|c|c|}
\hline & Combined seasons & Farrowing season & Winter period \\
\hline Habitat* & $\chi_{5}^{2}=6.65, P=0.25$ & $\chi_{5}^{2}=8.22, P=0.15$ & $\chi_{5}^{2}=7.99, P=0.16$ \\
\hline Soil* & $\chi_{5}^{2}=4.47, P=0.48$ & $\chi_{5}^{2}=3.28, P=0.66$ & $\chi_{5}^{2}=5.51, P=0.36$ \\
\hline Entrance height $\dagger$ & $r_{\mathrm{S}}=-0.11, N=503, P=0.01$ & $r_{\mathrm{S}}=0.04, N=366, P=0.41$ & $r_{\mathrm{S}}=-0.10, N=500, P=0.03$ \\
\hline Entrance width $\dagger$ & $r_{S}=0.08, N=503, P=0.08$ & $r_{\mathrm{S}}=0.07, N=366, P=0.21$ & $r_{S}=0.09, N=500, P=0.06$ \\
\hline Burrow density $\dagger$ & $r_{\mathrm{S}}=-0.11, N=509, P=0.02$ & $r_{S}=-0.04, N=371, P=0.45$ & $r_{\mathrm{S}}=-0.10, N=506, P=0.03$ \\
\hline Distance to water $\dagger$ & $r_{S}=0.08, N=509, P=0.07$ & $r_{\mathrm{S}}=0.03, N=371, P=0.53$ & $r_{\mathrm{S}}=0.10, N=506, P=0.02$ \\
\hline
\end{tabular}

* Kruskal-Wallis tests.

Spearman rank correlations. 
Table 4

Summary of hypotheses and evidence for factors influencing communal nesting in warthogs

\begin{tabular}{|c|c|c|}
\hline Factors affecting communal nesting & Hypotheses & Evidence \\
\hline \multirow[t]{3}{*}{ Ecological constraints } & $\begin{array}{l}\text { High dispersal costs promote philopatry (Blumstein \& Armitage } \\
\text { 1999; Lacey 2004) }\end{array}$ & $\begin{array}{l}\text { Not supported: philopatry does not necessitate communal } \\
\text { nesting, but dispersal costs may result in high levels of } \\
\text { philopatry }\end{array}$ \\
\hline & $\begin{array}{l}\text { Dispersal limited by clumped resources (Jarvis et al. 1994; } \\
\text { Faulkes et al. 1997; Johnson et al. 2002) }\end{array}$ & $\begin{array}{l}\text { Not tested, but unlikely to play a role in most herbivorous } \\
\text { species (Russell 2004) }\end{array}$ \\
\hline & Limitations in burrow sites (Lacey \& Sherman 1997) & Not supported \\
\hline Thermoregulatory requirements & $\begin{array}{l}\text { Communal nesting reduces individual thermoregulatory costs } \\
\text { (McCracken 1984; Pilastro 1992; Armitage 1999) }\end{array}$ & Not supported: burrow sharing was not affected by season \\
\hline Predator/infanticide defence & $\begin{array}{l}\text { Sharing of a nest increases survival of offspring through group } \\
\text { defence, by ensuring the presence of a babysitter, or through } \\
\text { dilution effects (East et al. 1989; Hoogland et al. 1989; Manning } \\
\text { et al. 1995; McNutt \& Silk 2008) }\end{array}$ & $\begin{array}{l}\text { Possible role supported: females combined litters into a } \\
\text { communal burrow although other burrows were available }\end{array}$ \\
\hline Resource/skill acquisition & $\begin{array}{l}\text { Communal nesting promotes exchange of knowledge (Getz et al. } \\
\text { 1992a; Wolff 1994) }\end{array}$ & $\begin{array}{l}\text { Not supported: resources are evenly distributed and nest } \\
\text { sharing includes sharing of burrows by multiple experienced } \\
\text { mothers without nonreproductive helpers }\end{array}$ \\
\hline
\end{tabular}

\section{Acknowledgments}

This research would not have been possible without Bohm Ndwandwe, who served as our guard during the duration of this study. Dumisane Khumalo, Grant Burden, Juan Steyn and Morgan Lind-Robinson provided help with data collection. Paul Havemann provided necessary logistical support and additional assistance in the field. This work was improved with comments by Mary Peacock, Luis Gomez-Raya, Steve Jenkins and Jeanne Zeh. Dan Blumstein, Luis Ebensperger and an anonymous referee made particularly helpful comments that improved this manuscript substantially. This study was conducted under the permission of KwaZulu-Natal Wildlife and complies with the laws of South Africa.

\section{References}

Armitage, K. B. 1999. Evolution of sociality in marmots. Journal of Mammalogy, 80, $1-10$.

Blumstein, D. T. \& Armitage, K. B. 1999. Cooperative breeding in marmots. Oikos, 84, 369-382.

Burroughs, R. E. J. 1993. Chemical capture of the warthog Phacochoerus aethiopicus. In: The Capture and Care Manual: Capture, Care, Accommodation and Transportation of Wild African Animals (Ed. by A. A. McKenzie), pp. 621-623. Pretoria: Wildlife Decision Support Services.

Cockburn, A. 1998. Evolution of helping behavior in cooperatively breeding birds. Annual Review of Ecology and Systematics, 29, 141-177.

Cohen, J. 1988. Statistical Power Analysis for the Behavioral Sciences. 2nd edn. Hillsdale, New Jersey: L. Erlbaum.

Cumming, D. H. M. 1975. A Field Study of the Ecology and Behaviour of Warthog Salisbury, Rhodesia: Trustees of the National Museums and Monuments of Rhodesia.

Dora, C. A. 2004. The influence of habitat structure and landscape heterogeneity on African buffalo (Syncerus caffer) group size in Hluhluwe-iMfolozi Game Reserve, South Africa. M.S. thesis, Oregon State University.

East, M., Hofer, H. \& Turk, A. 1989. Functions of birth dens in spotted hyaenas (Crocuta crocuta). Journal of Zoology, 219, 690-697.

Ebensperger, L. A. 1998. Strategies and counterstrategies to infanticide in mammals. Biological Reviews of the Cambridge Philosophical Society, 73, $321-346$.

Ebensperger, L. A. \& Bozinovic, F. 2000. Communal burrowing in the hystricognath rodent, Octodon degus: a benefit of sociality? Behavioral Ecology and Sociobiology, 47, 365-369.

Emlen, S. T. 1982. The evolution of helping I. An ecological constraints model. American Naturalist, 119, 29-39.

Emlen, S. T. 1991. Cooperative breeding in birds and mammals. In: Behavioral Ecology: an Evolutionary Approach (Ed. by J. R. Krebs \& N. B. Davies), pp. 301 337. Oxford: Blackwell Scientific.

Emlen, S. T. 1994. Benefits, constraints and the evolution of family. Trends in Ecology E' Evolution, 9, 282-285.

Estes, R. D. 1991. The Behavior Guide to African Mammals. Berkeley: University of California Press.
Faulkes, C. G., Bennett, N. C., Bruford, M. W., O’Brien, H. P., Aguilar, G. H. \& Jarvis, J. U. M. 1997. Ecological constraints drive social evolution in the African mole-rats. Proceeding of the Royal Society of London, Series B, 264, 1619-1627.

Funston, P. J., Mills, M. G. L. \& Biggs, H. C. 2001. Factors affecting the hunting success of male and female lions in the Kruger National Park. Journal of Zoology, 253, 419-431.

Garshelis, D. L. 2000. Delusions in habitat evaluation: measuring use, selection, and importance. In: Research Techniques in Animal Ecology. Controversies and Consequences (Ed. by L. Boitani \& T. K. Fuller), pp. 111-164. New York: Columbia University Press.

Getz, L. L., Larson, C. M. \& Lindstrom, K. A. 1992a. Blarina brevicauda as a predator of nestling voles. Journal of Mammalogy, 73, 591-596.

Getz, L. L., Gutermuth, D. F. \& Benson, S. M. 1992b. Pattern of nest occupancy of the prairie vole, Microtus ochrogaster, in different habitats. American Midland Naturalist, 128, 197-202.

Hayes, L. D. 2000. To nest communally or not to nest communally: a review of rodent communal nesting and nursing. Animal Behaviour, 59, 677-688.

Hayes, L. D., Chesh, A. S. \& Ebensperger, L. A. 2007. Ecological predictors of range areas and use of burrow systems in the diurnal rodent, Octodon degus. Ethology, 113, 155-165.

Hoogland, J. L. 1985. Infanticide in prairie dogs: lactating females kill offspring of their own kin. Science, 230, 1037-1040.

Hoogland, J. L., Tamarin, R. H. \& Levy, C. K. 1989. Communal nursing in prairie dogs. Behavioral Ecology Sociobiology, 24, 91-95.

Jacquot, J. J. \& Vessey, S. H. 1994. Non-offspring nursing in the white-footed mouse, Peromyscus leucopus. Animal Behaviour, 48, 1238-1240.

Jarvis, J. U. M., O'Riain, J. M., Bennett, N. C. \& Sherman, P. W. 1994. Mammalian eusociality: a family affair. Trends in Ecology \& Evolution, 9, 47-51.

Johnson, D. D. P., Kays, R., Blackwell, P. G. \& Macdonald, D. W. 2002. Does the resource dispersion hypothesis explain group living? Trends in Ecology \& Evolution, 17, 563-570.

Kinlaw, A. 1999. A review of burrowing by semi-fossorial vertebrates in arid environments. Journal of Arid Environments, 41, 127-145.

Lacey, E. A. 2004. Sociality reduces individual direct fitness in a communally breeding rodent, the colonial tuco-tuco (Ctenomys sociabilis). Behavioral Ecology and Sociobiology, 56, 449-457.

Lacey, E. A. \& Sherman, P. W. 1997. Cooperative breeding in naked mole-rats: implications for vertebrate and invertebrate sociality. In: Cooperative Breeding in Mammals (Ed. by N. G. Solomon \& J. A. French), pp. 267-301. New York: Cambridge University Press.

Lovegrove, B. G. 1989. The cost of burrowing by the social mole rats (Bathyergidae) Cryptomys damarensis and Heterocephalus glaber: the role of soil moisture. Physiological Zoology, 62, 449-469.

McCracken, G. F. 1984. Communal nesting in Mexican free-tailed bat maternity colonies. Science, 223, 1090-1091.

McNutt, J. W. \& Silk, J. B. 2008. Pup production, sex ratios, and survivorship in African wild dogs, Lycaon pictus. Behavioral Ecology and Sociobiology, 62, 1061-1067.

Manning, C. J., Dewsbury, D. A., Wakeland, E. K. \& Potts, W. K. 1995. Communal nesting and communal nursing in house mice, Mus musculus domesticus. Animal Behaviour, 50, 741-751.

Mason, D. R. 1982. Studies on the biology and ecology of the warthog Phacochoerus aethiopicus sundevalli Lonnberg, 1908. Ph.D. thesis, University of Pretoria, South Africa.

Moehlman, P. D. \& Hofer, H. 1997. Cooperative breeding, reproductive suppression, and body mass in canids. In: Cooperative Breeding in Mammals (Ed. by N. G. Solomon \& J. A. French), pp. 76-128. Cambridge: Cambridge University Press. 
8

A.M. White, E.Z. Cameron / Animal Behaviour xxx (2008) 1-8

Mohr, C. O. 1947. A table of equivalent populations of North American small mammals. American Midland Naturalist, 37, 223-249.

Muwanika, V. B., Nyakaana, S., Sigismund, H. R. \& Arctander, P. 2006. Population genetic structure of the common warthog (Phacochoerus africanus) in Uganda: evidence for a strong philopatry among warthogs and social structure breakdown in a disturbed population. African Journal of Ecology, 45, 22-30.

Ovsyanikov, N. 1998. Den use and social interactions of polar bears during spring in a dense denting area on Herald Island, Russia. Ursus, 10, 251-258.

Pilastro, H. 1992. Communal nesting between breeding females in a free-living population of fat dormouse (Elis gris L). Bollettino di Zoologia, 59, 63-68.

Plesner Jensen, S., Siefert, L., Okori, J. J. L. \& Clutton-Brock, T. H. 1999. Age-related participation in allosuckling by nursing warthogs Phacochoerus africans. Journal of Zoology, 248, 443-449.

Rood, J. P. 1986. Ecology and social evolution in the mongooses. In: Ecological Aspects of Social Evolution: Birds and Mammals (Ed. by D. I. Rubinstein \& R. W. Wrangham), pp. 131-152. Princeton, New Jersey: Princeton University Press.

Russell, A. F. 2004. Mammals: comparisons and contrasts. In: Ecology and Evolution of Cooperative Breeding in Birds (Ed. by W. D. Koenig \& J. L. Dickinson), pp. 210227. Cambridge: Cambridge University Press.

Sachot, S., Perrina, N. \& Ret, C. 2003. Winter habitat selection by two sympatric forest grouse in western Switzerland: implications for conservation. Biological Conservation, 112, 373-382.

Schradin, C. \& Pillay, N. 2006. Female striped mouse (Rhabdomys pumilio) change their home ranges in response to seasonal variation in food availability. Behavioral Ecology, 17, 452-458.

Seryodkin, I. V., Kostyria, A. V., Goodrich, J. M., Miquelle, D. G., Smirnov, E. N., Kerley, L. L., Quigley, H. B. \& Hornocker, M. G. 2003. Denting ecology of brown bears and Asiatic black bears in the Russian far east. Ursus, 14, 153-161.
Silk, J. B. 2007. The adaptive value of sociality in mammalian groups. Philosophical Transactions of the Royal Society of London, Series B, 362, 539-559.

Skinner, J. D. \& Chimimba, C. T. 2005. The Mammals of the Southern African Subregion. 3rd en. Cambridge: Cambridge University Press.

Solomon, N. G. \& French, J. A. 1997. The study of mammalian cooperative breeding. In: Cooperative Breeding in Mammals (Ed. by N. G. Solomon \& J. A. French), pp. 1-10. New York: Cambridge University Press.

Solomon, N. G. \& Getz, L. L. 1997. Examination of alternative hypotheses for cooperactive breeding in rodents. In: Cooperative Breeding in Mammals (Ed. by N. G. Solomon \& J. A. French), pp. 199-230. Cambridge: Cambridge University Press.

Sowers, M. J. 1992. Implications of social structure for the conservation and control of a warthog Phacochoerus aethiopicus population in the Andres Vosloo Kudu Reserve, Eastern Cape Province. M.S. thesis, University of Pretoria, South Africa.

Sowers, M. J., Penzhorn, B. L. \& Rosa, A. E. 1994. Home range size, range use and dispersal of warthogs in the eastern Cape, South Africa. Journal of African Zoology, 108, 361-373.

Sowers, M. J., Rasa, O. A. E. \& Penzhorn, B. L. 1995. Group structure and social behaviour of warthogs Phacochoerus aethiopicus. Act Theriologica, 40, 257-281.

Sows, L. K. \& Phelps, R. J. 1966. Body temperature of juvenile warthogs and bushpigs. Journal of Mammalogy, 47, 134-137.

Spinage, C. A. 1972. African ungulate life tables. Ecology, 53, 645-652.

Stacey, P. B. \& Lignon, J. D. 1987. Territory quality and dispersal options in the acorn woodpecker, and a challenge to the habitat-saturation model of cooperative breeding. American Naturalist, 130, 654-676.

Wolff, J. O. 1994. Reproductive success of solitary and communally nesting whitefooted mice and deer mice. Behavioral Ecology, 5, 206-209.

Zabala, J., Zuberogoitia, I., Grin, I. \& Aihartza, J. 2003. Landscape features in the habitat selection of European mink (Mustela lutreola) in south-western Europe. Journal of Zoology, 260, 415-421.

Please cite this article in press as: Angela M. White, Elissa Z. Cameron, Communal nesting is unrelated to burrow availability in the common

warthog, Animal Behaviour (2008), doi:10.1016/j.anbehav.2008.08.030 